\title{
A new labeling method for methyl TROSY NMR spectra of alanine residues
}

\author{
Rivka L. Isaacson, Peter J. Simpson, Minhao Liu, Ernesto Cota, Xiaodong Zhang, Paul \\ Freemont, and Stephen Matthews \\ Division of Molecular Biosciences, Faculty of Natural Sciences, Imperial College London, South \\ Kensington, London, UK
}

\begin{abstract}
The development of specific methyl labeling schemes and transverse relaxation optimized spectroscopy (TROSY) has extended the molecular size range for the application of NMR spectroscopy to proteins. Generally, methyl groups of isoleucine, leucine, valine residues are specifically protonated in a highly deuterated background and ${ }^{1} \mathrm{H}-{ }^{13} \mathrm{C}$ correlation experiments provide a means to study structure and dynamics in multimeric complexes with molecular weights far in excess of $100 \mathrm{kDa}$. We have extended this approach to alanine residues which offers several potential advantages, including its high abundance and wide distribution in protein sequences together with a high tolerance to mutation. We have developed an efficient method for the synthesis and incorporation of L-alanine- $3-{ }^{13} \mathrm{C}, 2-{ }^{2} \mathrm{H}$ into protein sequences. We also demonstrate the usefulness of specific protonation of alanine residues in combination with methyl TROSY experiments on the $306 \mathrm{kDa}$ fragment of the eukaryotic AAA-ATPase, p97, in complex with one of its many adaptor proteins.
\end{abstract}

The development of new isotopic labeling schemes has extended the molecular size range for the application of NMR spectroscopy to biological macromolecules. Notably, combining perdeuteration with the site-specific protonation of methyl groups provides a viable route for NMR-based structure determination of medium to large proteins ( $<100 \mathrm{kDa}) 1-6$.

Furthermore, transverse relaxation optimized spectroscopy (TROSY)7 of methyl-protonated samples offers genuine promise for obtaining high quality NMR spectra of very large systems (>100kDa)8-10. Methyl TROSY experiments confer substantial sensitivity enhancements by exploiting the cancellation of intra-methyl ${ }^{1} \mathrm{H}_{-}{ }^{1} \mathrm{H}$ and ${ }^{1} \mathrm{H}_{-}{ }^{13} \mathrm{C}$ dipoledipole relaxation mechanisms 11,12 . Typically, ${ }^{1} \mathrm{H}_{-}{ }^{13} \mathrm{C}$ correlation spectra are recorded on samples with methyl-specific protonation of isoleucine, leucine, valine (ILV) residues in a highly deuterated background; a recent triumph being a study on the $670 \mathrm{kDa} 20 \mathrm{~S}$ proteasome core particle from archeabacterium Thermoplasma acidophilum8. A major obstacle in this approach is the unambiguous chemical shift assignment of the labeled methyl groups in very large systems, which is only possible if comprehensive NMR data are available on smaller fragments. Site-directed mutagenesis can assist in making assignments by creating mutants that remove or introduce new methyl groups. An attractive alternative would be to label alanine, since it is one of the most abundant amino acids found in proteins $(8.3 \%) 13$, is widely distributed in both protein cores and surfaces 14 and mutagenesis is well tolerated 15 , particularly the introduction of alanine residues into new positions.

At the moment two principal problems prevent the use of alanine in methyl TROSY experiments. First, alanine plays a central role in several E. coli biosynthetic pathways, which results in significant incorporation of the labeled precursor into other methyl- 
containing amino acids. Although selective labeling has been reported in minimal medium supplemented with specific amino acids designed to suppress scrambling16, this strategy is not practical for background perdeuteration. Second, the precursor for preparing alaninelabeled samples tailored for TROSY experiments is not available commercially i.e. Lalanine with ${ }^{1} \mathrm{H},{ }^{13} \mathrm{C}$ labeling at the methyl position and deuterated at the 2-carbon position (L-alanine- $3-{ }^{13} \mathrm{C}, 2-{ }^{2} \mathrm{H}$ ). We therefore set out to resolve these issues and demonstrate the benefits of alanine labeling in methyl TROSY experiments on a number of protein systems currently under study in our laboratory. Namely, the eukaryotic AAA-ATPase, p97, which is a versatile molecular motor that provides the energy/mechanical force for a wide range of cellular processes17 and an adaptor complex of p97, the heterodimeric Ufd1-Npl4 (UN)18, which by association with p97 plays fundamental roles in Endoplasmic ReticulumAssociated Degradation (ERAD) and Regulated Ubiquitin-dependent Processing (RUP).

As a first step we developed a procedure for the synthesis of L-alanine- $3-{ }^{13} \mathrm{C}, 2-{ }^{2} \mathrm{H}$. Pyridoxal phosphate-dependent enzymes catalyze a wide range of reactions, many of which involve cleavage of the a-proton bond of L-amino acids, for example in the reactions of tryptophan synthase. The kinetics of this process have been well characterized19 and were exploited in designing a simple procedure for the preparation of L-alanine- $3-{ }^{13} \mathrm{C}, 2-{ }^{2} \mathrm{H}$ from protonated L-alanine-3- ${ }^{13} \mathrm{C}$, which is widely available commercially and affordable.

Furthermore, we present a protocol for its efficient incorporation into perdeuterated proteins.

Salmonella typhimurium tryptophan synthase $\alpha_{2} \beta_{2}$ complex was purified using an adaptation of the described protocol20. In summary, the recombinantly-produced enzyme was crystallized from $\mathrm{D}_{2} \mathrm{O}$ buffer, isolated and added directly to a solution of Lalanine-3- ${ }^{13} \mathrm{C}$. (Supplementary Figure S1). After several days at room temperature deuteration at the 2-carbon was deemed complete as assessed by $1 \mathrm{D}{ }^{1} \mathrm{H}-\mathrm{NMR}$ spectroscopy $(>97 \%)$. The reaction mixture was subsequently added, without further purification, to the growth medium (at $50 \mathrm{mg} / \mathrm{L}$ alanine) for the production of alanine-labeled proteins. As significant scrambling of the label would be envisaged in an M9-based medium, we therefore chose to use a deuterated 'rich' medium without further supplementation (Supplementary information). Furthermore, this approach offers the advantage that higher yields are usually achieved in such growth media, particularly for proteins that display expression difficulties under more frugal conditions.

To verify our approach we chose the $10 \mathrm{kDa}$ ubiquitin-like domain from Npl4 (Npl4-UBD), an $80 \mathrm{kDa}$ heterodimeric complex (UN) between the C-terminus of Ufd1 and Npl4 and the $306 \mathrm{kDa}$ hexameric fragment of p97, p97 ND1, for which high resolution structural information exists21. Figure 1 shows the ${ }^{1} \mathrm{H}_{-}{ }^{13} \mathrm{C}$ methyl TROSY spectra of the ${ }^{13} \mathrm{CH}_{3^{-}}$ Ala,U- ${ }^{2} \mathrm{H}$ labeled samples. For UN (Figure 1A) and Npl4-UBD (Figure S2) the exact number of expected alanine resonances can be observed with no detectable scrambling of the labeled alanine precursor (Supplementary Figure S2). Interestingly, the poor chemical shift dispersion for alanine resonances in UN spectra indicate that this region of the Ufd1 fragment is not highly structured. In spectra of the $306 \mathrm{kDa}$ p97 ND1 (Figures 1C and S4), many of the expected 38 correlations from alanine residues can be resolved in the spectrum. Assignment for alanine residues in the $\mathrm{N}$ domain 22 could be readily transferred to the methyl TROSY spectra as the chemical shifts match closely (Supplementary Figure S3). To estimate the level of incorporation a second methyl-labeled sample was prepared with the addition of ${ }^{13} \mathrm{CH}_{3}$-a-ketobutyric acid (which results in the incorporation of ${ }^{13} \mathrm{C}_{\delta} \mathrm{H}_{3}$ in Ile residues) as well as L-alanine- $3-{ }^{13} \mathrm{C}, 2-{ }^{2} \mathrm{H}$ to the growth medium. Figure $1 \mathrm{C}$ indicates that both alanine and isoleucine residues are labeled to comparable levels. These data together with labeling experiments performed in a protonated background (data not shown), provide an estimate for the level of alanine incorporation to be $>75 \%$. 
The huge potential of the ${ }^{1} \mathrm{H}-{ }^{13} \mathrm{C}$ methyl TROSY approach lies in following interactions and dynamics in very large protein complexes. While the ILV labeling provides reasonable coverage of protein sequences, a wider sequence analysis reveals that alanine is the only methyl-containing, non-polar amino acid residue that has a high propensity to occur exposed in interfaces23. To demonstrate the usefulness of methyl TROSY of alanine residues on mapping interactions, spectra were recorded on p97 ND1 in complex with Np14-UBD18. Clear chemical shift changes are observed in the methyl TROSY spectra of ${ }^{13} \mathrm{CH}_{3}$-Ala, U- ${ }^{2} \mathrm{H}$ labeled p97 ND1 in the presence of saturating amounts of perdeuterated Npl4-UBD (Figure 1D). All of the significantly shifted resonances localize exclusively to the $\mathrm{N}$ domains at the extremity of the hexameric ring. Furthermore, two of the most perturbed alanine residues (A177 and A142) lie directly within the interface identified from 15N NMR data on the monomeric, $24 \mathrm{kDa}$ p97 $\mathrm{N}$ fragment22. A160 and A67 are more distant from the interface and these changes may reflect a subtle reorientation of $\mathrm{N}$ domain. This represents the first detailed structural insight into the interaction of hexameric p97 with UN.

In conclusion, we have developed an efficient method for the synthesis and incorporation of L-alanine-3- ${ }^{13} \mathrm{C}, 2-{ }^{2} \mathrm{H}$ into protein sequences. We also demonstrate the usefulness of specific protonation of alanine residues in combination with methyl TROSY experiments and extend the scope of the ILV-approach in studying large, multimeric complexes. Furthermore, the approach can be used in conjunction with, for example, ${ }^{13} \mathrm{C}_{\delta} \mathrm{H}_{3}$ labeling of Ile residues if alanine-only labeling was not sufficient to characterize the system under study.

\section{Supplementary Material}

Refer to Web version on PubMed Central for supplementary material.

\section{Acknowledgments}

The research is supported by grants 080093 and 079819 from the Wellcome Trust. The authors would also like to acknowledge Prof Paul Malthouse for kindly providing E. coli strains expressing tryptophan synthase complex.

\section{References}

(1). Jordan JB, Kovacs H, Wang YF, Mobli M, Luo RS, Anklin C, Hoch JC, Kriwacki RW. JACS. 2006; 128:9119-28.

(2). Tugarinov V, Choy WY, Orekhov VY, Kay LE. PNAS. 2005; 102:622-7. [PubMed: 15637152]

(3). Kelly G, Prasannan S, Daniell S, Fleming K, Frankel G, Dougan G, Connerton I, Matthews S. Nature Struct. Biol. 1999; 6:313-8. [PubMed: 10201396]

(4). Zwahlen C, Gardner KH, Sarma SP, Horita DA, Byrd RA, Kay LE. JACS. 1998; 120:7617-25.

(5). Gardner KH, Rosen MK, Kay LE. Biochemistry. 1997; 36:1389-401. [PubMed: 9063887]

(6). Fernández C, Hilty C, Wider G, Güntert P, Wüthrich K. J. Mol. Biol. 2004; 336:1211-21. [PubMed: 15037080]

(7). Pervushin K, Riek R, Wider G, Wüthrich K. PNAS. 1997; 94:12366-71. [PubMed: 9356455]

(8). Sprangers R, Kay LE. Nature. 2007; 445:618-22. [PubMed: 17237764]

(9). Sprangers R, Gribun A, Hwang PM, Houry WA, Kay LE. PNAS. 2005; 102:16678-83. [PubMed: 16263929]

(10). Hamel DJ, Dahlquist FW. JACS. 2005; 127:9676-7.

(11). Tugarinov V, Hwang PM, Ollerenshaw JE, Kay LE. JACS. 2003; 125:10420-8.

(12). Tugarinov V, Kay LE. J. Biomol. NMR. 2004; 28:165-72. [PubMed: 14755160]

(13). McCaldon P, Argos P. Proteins-Struct. Funct. Genet. 1988; 4:99-122. [PubMed: 3227018]

(14). Tjong H, Qin S, Zhou H-X. Nucleic Acids Res. 2007; 35:W357-W62. [PubMed: 17526530]

(15). Brown BM, Sauer RT. PNAS. 1999; 96:1983-8. [PubMed: 10051581] 
(16). Serber Z, Straub W, Corsini L, Nomura AM, Shimba N, Craik CS, de Montellano PO, Dötsch V. JACS. 2004; 126:7119-25.

(17). Dreveny I, Pye VE, Beuron F, Briggs LC, Isaacson RL, Matthews SJ, McKeown C, Yuan X, Zhang X, Freemont PS. Biochemical Society Transactions. 2004; 32:715-20. [PubMed: 15493996]

(18). Meyer HH, Shorter JG, Seemann J, Pappin D, Warren G. EMBO J. 2000; 19:2181-92. [PubMed: 10811609]

(19). Milne JJ, Malthouse JPG. Biochem. J. 1996; 314:787-91. [PubMed: 8615770]

(20). Miles EW, Kawasaki H, Ahmed SA, Morita H, Morita H, Nagata S. J. Biol. Chem. 1989; 264:6280-7. [PubMed: 2495283]

(21). Zhang XD, Shaw A, Bates PA, Newman RH, Gowen B, Orlova E, Gorman MA, Kondo H, Dokurno P, Lally J, Leonard G, Meyer H, van Heel M, Freemont PS. Mol. Cell. 2000; 6:147384. [PubMed: 11163219]

(22). Isaacson RL, Pye VE, Simpson P, Meyer HH, Zhang XD, Freemont PS, Matthews S. J. Biol. Chem. 2007; 282:21361-9. [PubMed: 17491009]

(23). Fernández A, Scott LR, Scheraga HA. J. Phys. Chem. 2003; 107:9929-32. 




D
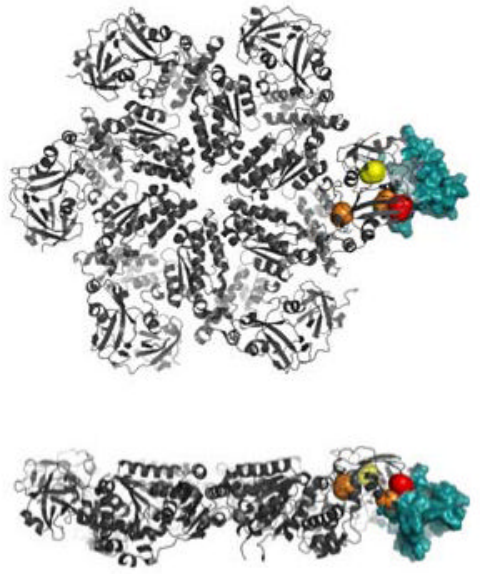
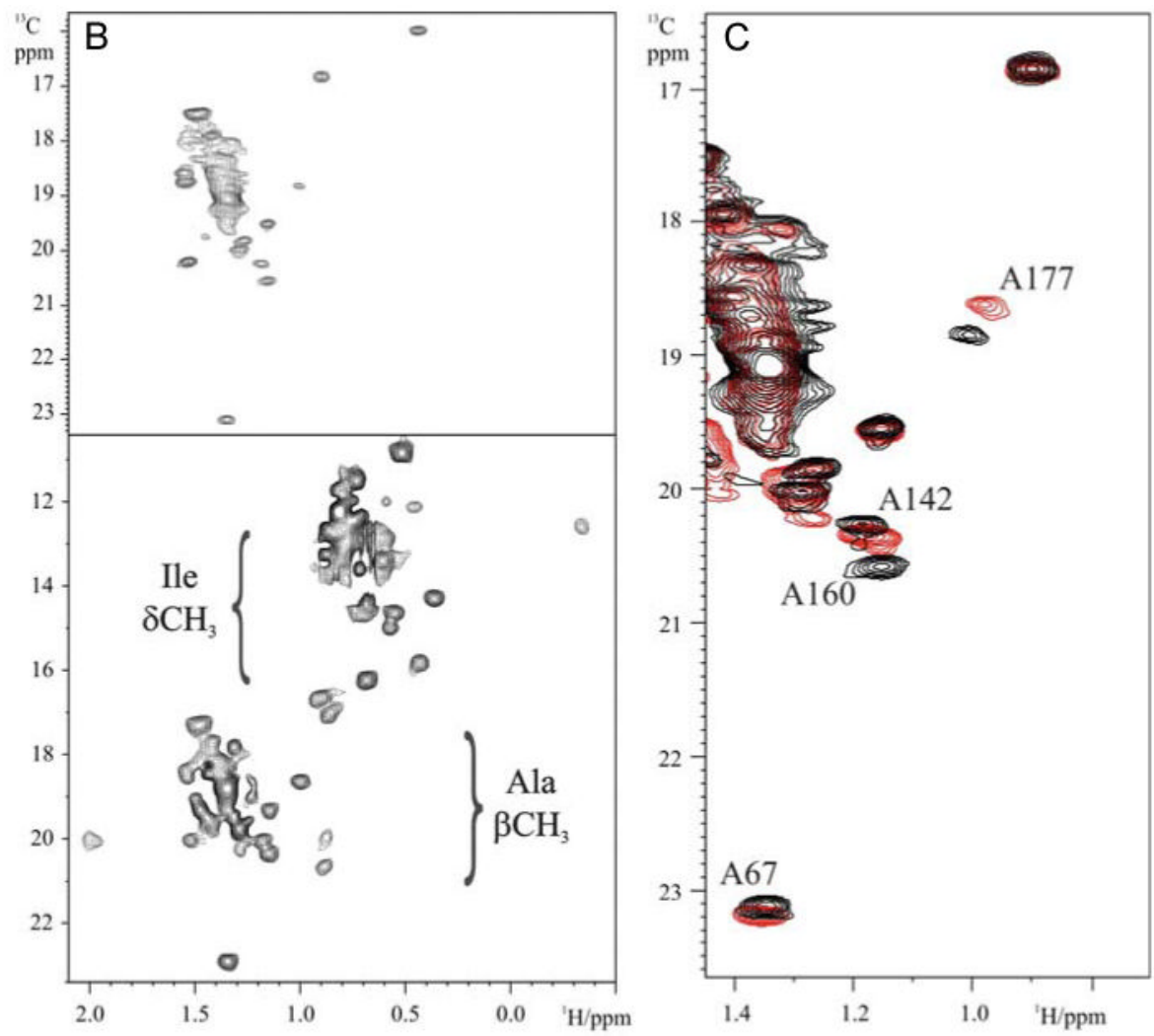

Figure 1.

Alanine labeling and ${ }^{1} \mathrm{H}_{-}{ }^{13} \mathrm{C} 2 \mathrm{D}$ Methyl TROSY spectra of (A) ${ }^{13} \mathrm{CH}_{3}-\mathrm{Ala}, \mathrm{U}-{ }^{2} \mathrm{H}$ labeled Ufd1in UN (B) ${ }^{13} \mathrm{CH}_{3}$-Ala, $\mathrm{U}^{2} \mathrm{H}$ labeled p97 ND1 (top) and ${ }^{13} \mathrm{C}_{\delta} \mathrm{H}_{3}$-Ile, ${ }^{13} \mathrm{CH}_{3}$-Ala,U- ${ }^{2} \mathrm{H}$ labeled p97ND1 (bottom) (C) Expanded region of the ${ }^{1} \mathrm{H}_{-}{ }^{13} \mathrm{C} 2 \mathrm{D}$ Methyl TROSY spectrum of ${ }^{13} \mathrm{CH}_{3}$-Ala, $\mathrm{U}_{-}{ }^{2} \mathrm{H}$ labeled p97 ND1 in the absence and presence of perdeuterated Npl4 UBD. (D) Structural model of the p97 ND1-Np14 UBD complex. The p97 hexamer is shown as a grey ribbon and perturbed alanine residues are indicated by red (most shifted), orange (intermediate) and yellow (least) balls. The position of Np14 UBD (blue surface) in complex with p97 N domain is shown for one of monomers. Details are given in supplementary information. 